ago out of curiosity, coupled with the excitement of going to sea. The field has expanded hugely since then: the research is still fun, but it is now more essential than ever to get it right.

In the early days of exploration, European nations competed to find sea routes to Asia around the southern rim of Africa, or to the great unknown to the west. The southern route succeeded; the western route led to gold, to the great misfortune of those who had arrived there earlier. Even then, some explorers were intrigued by ocean currents as a means to speed up their journey, and by the origin of the cool, tropical subsurface water in which they cooled off.

Gradually these explorers morphed into scientists, although sea-going oceanographers still retain an element of the explorer. We are now armed with more sophisticated tools to measure the ocean's fluctuations - from aboard ships, from instruments moored or floating freely in the ocean, and from satellites peering down from above. Considering salt water's high density - granite is only 2.5 times more dense - and its high heat capacity and latent heat, it's no wonder the vast ocean mass has a lock on the climate. Unfortunately, our inability to simulate properly the ocean processes that transfer heat, water and dissolved chemicals undermines the validity of our global climate models. And there is that annoying dab of carbon dioxide that we are so unwisely burning into the atmosphere, half of which ends up acidifying the ocean.

Oceanographers spend many weeks aboard ship, enduring the rolling and pitching that strains brain and belly. Murphy discovered this uncomfortable truth as a technician aboard the Woods Hole Oceanographic Institution's research vessel Oceanus and on two cruises aboard the US National Oceanic and Atmospheric Administration's Ronald H. Brown. He learned that big science, with its multifaceted programmes involving numerous institutions and countries, boils down to a small band of oceanographers tending to arrays of instruments over 24-hour watch schedules.

Murphy focuses on the North Atlantic meridional overturning circulation (MOC) of which the Gulf Stream is part - only briefly mentioning other areas of the ocean. The MOC causes warm waters from the top kilometre of the ocean to spread into the northern North Atlantic, where they cool and sink to return southwards; in the process, western Europe is warmed. Fear of a breakdown in the MOC in a warming climate is what motivates much of the big science of the North Atlantic. Past climate patterns suggest that the MOC may slow during cool phases, not warm ones, but causeand-effect issues need to be sorted out and a more global prospective is needed. Will global climate warming shut down the MOC and induce a cooling of northern Europe? I doubt it, but then the rapidly forced, anthropogenic modification of climate may not follow the same course as past natural changes.
Murphy effectively points out that although the ocean sciences are now more important than ever, funding is so inadequate that very few worthwhile projects receive support. Chasing grant money reduces researchers' productive time, and delays advances in understanding the sea; and the clock is ticking. Meanwhile, the public needs to know about the oceans, but oceanographers remain wary of media misrepresentation of their work. Meticulously following the waters of the Gulf Stream into the blue beyond, Murphy's book gets it right.

Arnold L. Gordon is professor of oceanography and associate director of the Division of Ocean and Climate Physics at the Lamont-Doherty Earth Observatory, Columbia University, Palisades, New York 10964-8000, USA.

\title{
EXHIBITION
}

\section{The invisible continent}

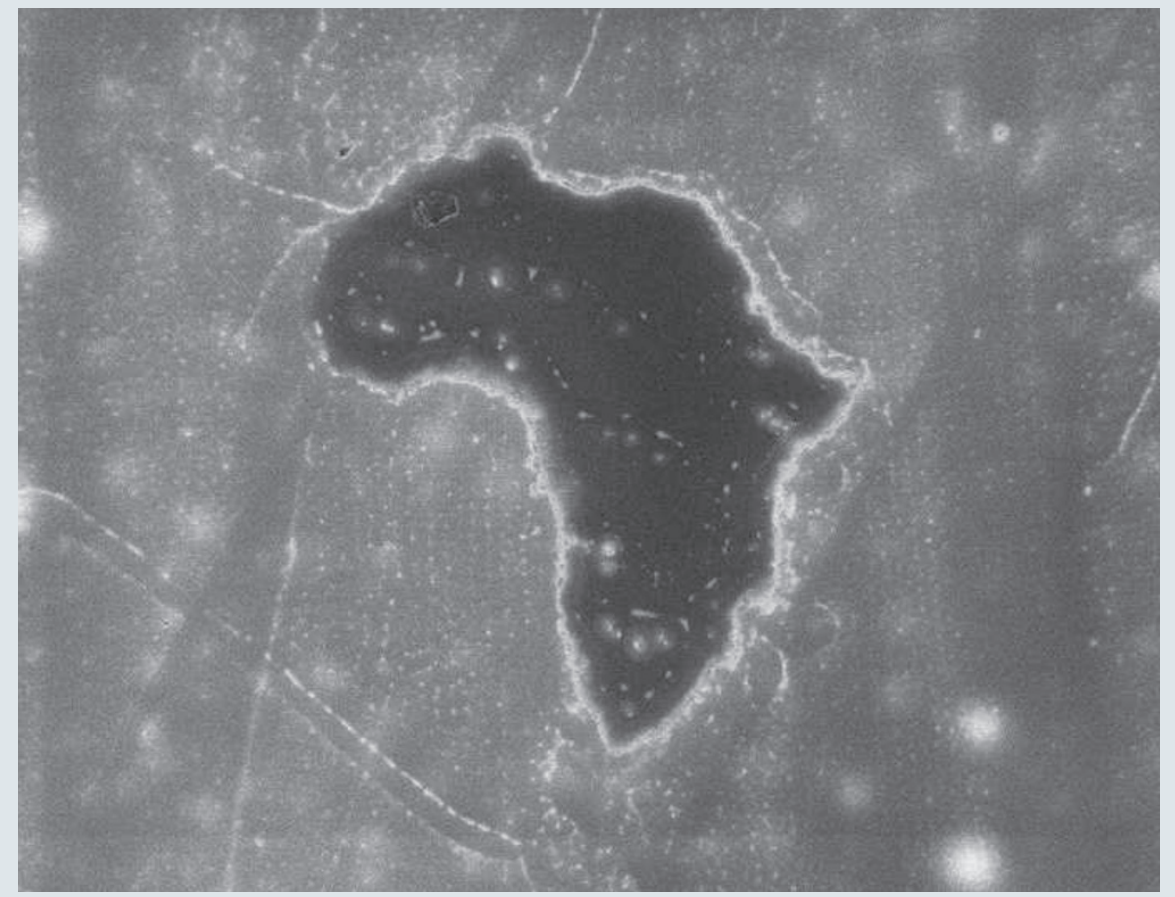

A tiny map of Africa, visible only with a microscope, represents a global paradox.

\section{Emiliano Feresin}

Satellite pictures of Earth have become too familiar to inspire awe. But two Turin-based artists have been prompted by the large-scale view of our planet - and by that other world, at the molecular level, that nanotechnologists can now reveal and manipulate.

Alessandro Scali from Turin, and Robin Goode, a South

African, conceived Actual Size, the smallest ever map of Africa. The artwork is a tiny sliver of silicon just a thousand or so atoms wide, made with atomic force microscopy, and visible only with the same technique. It is one of the 'nanoartworks' to be shown in the duo's first exhibition next month, as part of the Bergamo science festival in Italy.

"We know from books that Africa is the cradle of humanity, and we can see from maps and the beautiful satellite images that Africa is vast and is at the centre of the world," says Scali. "But we also know that Africa is poor, exploited, neglected." The artists wanted to represent the paradox of Africa being geographically and anthropologically central to our world, yet unrecognized, unexplored, even 'invisible'.

Scali and Goode brought their concept to Fabrizio Pirri, a physicist at Turin Polytechnic University. Pirri's group turned its atomic force microscope - usually used for biomedical engineering - to a modern form of lithography. Through electrical interaction, the microscope's 10-nanometrewide tip oxidized individual atoms of the silicon to trace the shape of Africa. They made dozens of copies before obtaining the unique piece that satisfied the artists. For the exhibition, Scali and Goode have made poster-size copies of their work, which could otherwise only be seen in the lab.

A second, larger version of Actual Size, as big as the point of a needle, will also be on show at Bergamo, and visible to visitors through a microscope. In this case, the scientists used a laser which removes atoms through sublimation - to etch the map onto silicon.

Emiliano Feresin is an intern in Nature's Munich office.

The exhibition Nan ${ }^{\circ}$ art runs 2-21 October in Bergamo, Italy. 